\title{
IMA genome - F14
}

\section{Draft genome sequences of Penicillium roqueforti, Fusarium sororula, Chrysoporthe puriensis, and Chalaropsis populi}

\author{
Magriet A. van der Nest ${ }^{1,2}$, Renato Chávez ${ }^{3 *}$, Lieschen De Vos ${ }^{1 *}$, Tuan A. Duong ${ }^{1 *}$, Carlos Gil-Durán ${ }^{3}$, \\ Maria Alves Ferreira ${ }^{4}$, Frances A. Lane ${ }^{1}$, Gloria Levicán ${ }^{3}$, Quentin C. Santana ${ }^{1}$, Emma T. Steenkamp¹, \\ Hiroyuki Suzuki ${ }^{1}$, Mario Tello ${ }^{3}$, Jostina R. Rakoma ${ }^{1}$, Inmaculada Vaca ${ }^{5}$, Natalia Valdés ${ }^{3}$, P. Markus Wilken ${ }^{1 *}$, \\ Michael J. Wingfield ${ }^{1}$ and Brenda D. Wingfield ${ }^{1}$
}

\begin{abstract}
Draft genomes of Penicillium roqueforti, Fusarium sororula, Chalaropsis populi, and Chrysoporthe puriensis are presented. Penicillium roqueforti is a model fungus for genetics, physiological and metabolic studies, as well as for biotechnological applications. Fusarium sororula and Chrysoporthe puriensis are important tree pathogens, and Chalaropsis populi is a soilborne root-pathogen. The genome sequences presented here thus contribute towards a better understanding of both the pathogenicity and biotechnological potential of these species.
\end{abstract}

Keywords: Fusarium fujikuroi species complex (FFSC), Colombia, Pinus tecunumanii, Eucalyptus leaf pathogen

\section{IMA GENOME - F 14A}

Draft genome sequence of Penicillium roqueforti CECT $2905^{\mathrm{T}}$

\section{Introduction}

Penicillium roqueforti is one of the economically most important fungal species within the genus Penicillium. This fungus is widely known in the food industry because it is responsible for the ripening of blue cheeses (Chávez et al. 2011). In addition, in recent years, P. roqueforti has acquired growing importance as a model fungus for genetics, physiological and metabolic studies, as well as for biotechnological applications (Coton et al. 2020).

Phylogenetically, $P$. roqueforti belongs to section Roquefortorum within the genus Penicillium (Houbraken

\footnotetext{
* Correspondence: renato.chavez@usach.cl; lieschen.bahlmann@fabi.up.ac.za; Tuan.Duong@fabi.up.ac.za; Markus.Wilken@fabi.up.ac.za

${ }^{3}$ Departamento de Biología, Facultad de Química y Biología, Universidad de Santiago de Chile (USACH), Alameda 3363, Estación Central, 9170022 Santiago, Chile

'Department of Biochemistry, Genetics and Microbiology, Forestry and Agricultural Biotechnology Institute (FABI), University of Pretoria, Private bag X20, Pretoria 0028, South Africa

Full list of author information is available at the end of the article
}

et al. 2020; Fig. 1). P. roqueforti was originally described by Thom (1906), and the nomenclatural type of the species is the neotype IMI 024313 (Frisvad and Samson 2004). From this neotype strain, several ex-type strains have been obtained, which are stored in different culture collections around the world.

Among the ex-type strains obtained from the neotype IMI 024313, P. roqueforti CECT $2905^{\mathrm{T}}$ is one of the most widely used. Many molecular studies have been carried out in this ex-type strain, including the analysis of regulatory genes of development and metabolism (García-Rico et al. 2009; Gil-Durán et al. 2015; Torrent et al. 2017; Rojas-Aedo et al. 2018), and importantly, $P$. roqueforti CECT $2905^{\mathrm{T}}$ has been used to demonstrate the functionality of all biosynthetic gene clusters (BGCs) for the production of secondary metabolites characterized so far in this fungal species (Hidalgo et al. 2014; Kosalková et al. 2015; Del-Cid et al. 2016; Fernández-Bodega et al. 2017; Rojas-Aedo et al. 2017).

Owing to the importance of P. roqueforti CECT $2905^{\mathrm{T}}$ as model for molecular studies and BGCs characterization, the availability of its genome would be very useful.

(c) The Author(s). 2021 Open Access This article is licensed under a Creative Commons Attribution 4.0 International License, which permits use, sharing, adaptation, distribution and reproduction in any medium or format, as long as you give

appropriate credit to the original author(s) and the source, provide a link to the Creative Commons licence, and indicate if changes were made. The images or other third party material in this article are included in the article's Creative Commons licence, unless indicated otherwise in a credit line to the material. If material is not included in the article's Creative Commons licence and your intended use is not permitted by statutory regulation or exceeds the permitted use, you will need to obtain permission directly from the copyright holder. To view a copy of this licence, visit http://creativecommons.org/licenses/by/4.0/ 


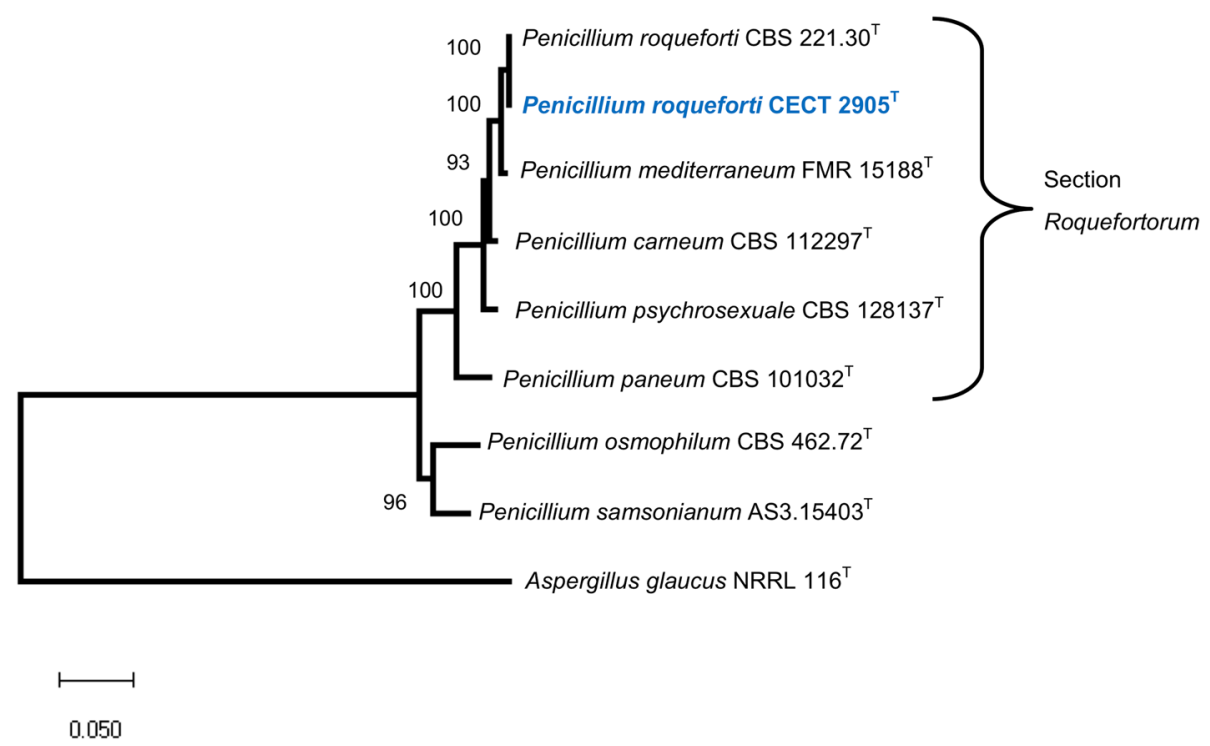

Fig. 1 Phylogenetic tree obtained after Maximum Likelihood analysis of the genome sequence of Penicillium roqueforti CECT $2905^{\top}$ and related species. The analysis was done as detailed in the Materials and methods section. Bootstrap support values $(>50 \%)$ are shown at the nodes (bootstrap iterations $=1000)$. The tree was rooted using combined BenA, CaM and RPB2 regions from Aspergillus glaucus NRRL $116^{\top} .^{\top}=$ ex-type strain

Consequently, we report this genome resource here. The availability of the genome of $P$. roqueforti CECT $2905^{\mathrm{T}}$ will facilitate future studies on the functional characterization of further BGCs and genes related with the regulation of development and metabolism in this important fungal species.

\section{Sequenced strain}

USA: Connecticut: Storrs, isol. ex French Roquefort cheese, 1904, C. Thom (CECT 2905 ${ }^{\mathrm{T}}$, ex-type strain from the neotype IMI 024313).

\section{Nucleotide sequence accession number}

The genome sequence of Penicillium roqueforti CECT $2905^{\mathrm{T}}$ has been deposited in the DDBJ/ENA/ GenBank databases under the accession number MSQC00000000; Bio project PRJNA351232; Bio-sample SAMN05951162. The version described in this paper is version MSQC00000000.

\section{Materials and methods}

Penicillium roqueforti CECT $2905^{\mathrm{T}}$ was grown on CM broth as described before (Gil-Durán et al. 2015). Mycelium was harvested, washed with $\mathrm{NaCl} 0.9 \%$, and highmolecular weight DNA was extracted exactly as was described by Bainbridge et al. (1990).

High-molecular weight DNA from $P$. roqueforti CECT $2905^{\mathrm{T}}$ was sequenced using the Illumina HiSeq 2000 platform at Macrogen (Seoul, Korea). A pair-end library with insert sizes of $550 \mathrm{bp}$ was prepared using TruSeq DNA PCR Free kit, and used to generate 101 bp length reads. The quality of the data obtained was assessed using FastQC. Low quality data and adapters were removed with Trimmomatic v. 0.36 (Bolger et al. 2014). Genome assembly of high quality Illumina raw reads was performed with Bowtie2 v. 2.4.1 (Langmead and Salzberg 2012), using the genome of $P$. roqueforti FM164 (Cheeseman et al. 2014) as reference. The final assembly was subjected to completeness assessment using Benchmarking Universal Single-Copy Orthologs program (BUSCO v. 4.0.6; Seppey et al. 2019), utilizing Eurotiales odb10 dataset. Genes were predicted with AUGUSTUS v. 3.3.3 (Stanke et al. 2008) using the training dataset from Aspergillus nidulans. Finally, in order to identify BGCs, anti-SMASH fungal version v. 5 (Blin et al. 2019) was conducted with default parameters.

The phylogenetic analysis of $P$. roqueforti CECT $2905^{\mathrm{T}}$ and related species was done using combined $\beta$-tubulin $(\operatorname{Ben} A)$, calmodulin $(C a M)$ and RNA polymerase II second largest subunit (RPB2) regions (Guevara-Suarez et al. 2020). Sequences from related species were obtained from GenBank accessions reported by Houbraken et al. (2020), whereas those from $P$. roqueforti CECT $2905^{\mathrm{T}}$ were extracted from the sequence genome. Maximum Likelihood analysis was done in MegaX (Kumar et al. 2018) under GTR + G model.

\section{Results and discussion}

The phylogenetic tree based on the concatenated $\operatorname{Ben} A$, $C a M$ and $R P B 2$ regions confirmed that the sequenced genome belongs to the species $P$. roqueforti. $P$. roquefort $i$ CECT $2905^{\mathrm{T}}$ clustered together with $P$. roqueforti CBS 
$221.30^{\mathrm{T}}$ with a bootstrap support of $100 \%$. In addition, this $P$. roqueforti clade was clearly separated from the other five species within the Roquefortorum section (Fig. 1).

Table 1 summarizes the main metrics of the assembled genome sequence of $P$. roqueforti CECT $2905^{\mathrm{T}}$. The assembled draft genome has a total length of $26.1 \mathrm{Mb}$ corresponding to 1168 contigs with an N50 value of 70,366 bp, L50 value of 112, and an average GC content of $48.9 \%$. AUGUSTUS predicted 9015 protein coding genes, with an average gene density of 345.4 genes per $1 \mathrm{Mb}$. BUSCO analysis reported a completeness score of $98.8 \%$ based on the identification of 4141 complete and 18 fragmented genes from a total of 4191 Eurotiales genes searched. The estimated genome size of $P$. roqueforti CECT $2905^{\mathrm{T}}$ is comparable to that of other $P$. roqueforti strains found in databases, namely JCM 22842 (27.1 Mb; GenBank accession number BCID00000000), UASWS P1 (27.9 Mb; GenBank accession number JNNS01000000) and FM164 (28 Mb; Cheeseman et al. 2014).

The BGCs prediction performed with anti-SMASH fungal version yielded a total of 34 regions associated with biosynthesis of secondary metabolites. The BGCs found correspond to type I polyketide synthases (PKS), non-ribosomal peptide synthetases (NRPS), NRPS-like

Table 1 General characteristics of the genome of Penicillium roqueforti CECT $2905^{\top}$

\begin{tabular}{ll}
\hline Assembly metrics & \\
Total bases & $2,019,762,619$ \\
Read count & $22,375,066$ \\
GC (\%) & 48.9 \\
Number of contigs & 1168 \\
Assembly size (Mb) & 26.1 \\
N50 (bp) & 70,366 \\
L50 & 112 \\
Predicted genes models & 9015 \\
Gene density (genes per Mb) & 345.4 \\
BUSCO completeness & $98.8 \%$ \\
Biosynthetic gene clusters (BGCs) & \\
PKS type I & 9 \\
PKS type I-NRPS & 3 \\
NRPS & 7 \\
NRPS-indole & 1 \\
NRPS-like fragments & 6 \\
NRPS-like fragment-indole & 1 \\
Terpene & 1 \\
Beta-lactone & 1 \\
Indole & 1 \\
Siderophore & 2 \\
\hline
\end{tabular}

fragments, PKS-NRPS, NRPS-indole, NRPS-like-indole, terpene, siderophore, and beta-lactone. The number of BGCs predicted in this work is in good agreement with previous estimation by Coton et al. (2020) who suggested that strains of $P$. roqueforti would contain between 34 and 37 BGCs. To date, only six BGCs have been functionally characterized in $P$. roqueforti CECT $2905^{\mathrm{T}}$ (Hidalgo et al. 2014; Kosalková et al. 2015; DelCid et al. 2016; Fernández-Bodega et al. 2017; RojasAedo et al. 2017), so the availability of its draft genome, informed in this paper, will facilitate future studies of functional characterization of further BGCs in this important fungus.

Authors: Natalia Valdés, Mario Tello, Inmaculada Vaca, Carlos Gil-Durán, Gloria Levicán, and Renato Chávez

"Contact: renato.chavez@usach.cl

\section{IMA GENOME - F 14B}

Draft genome assembly of Fusarium sororula

\section{Introduction}

Fusarium species within the Fusarium fuikuroi species complex (FFSC) are plant pathogens of various cultivated crops of economic importance (Kvas et al. 2009; Leslie and Summerell 2006). As such, numerous FFSC species have their genomes sequenced, with the first, $F$. verticillioides, published in 2010 (Ma et al. 2010). Currently, 51 FFSC species have genome sequences publicly available (www.ncbi.nlm.nih.gov).

In a study exploring the diversity of FFSC species associated with Pinus species in Colombia, five new species were described (Herron et al. 2015). One of these, Fusarium sororula, was isolated from diseased $P$. tecunumanii seedlings that displayed symptoms of wilt, shoot dieback and roots with lesions that were resin soaked (Steenkamp et al. 2012). These are all symptoms typical of infection by the pitch canker pathogen, $F$. circinatum. This new species was able to cause disease on susceptible $P$. patula, at similar levels as F. circinatum (Herron et al. 2015). Fusarium sororula is consequently a threat to global commercial forestry and the availability of its genome sequence will contribute to studies aimed at better understanding its biology and genetics.

\section{Sequenced strain}

Colombia: Angela Maria, Santa Rosa, $75^{\circ} 36^{\prime} 21^{\prime \prime} \mathrm{W}$ $4^{\circ} 49^{\prime} 18^{\prime \prime} \mathrm{N}$, isolated from diseased Pinus tecunumanii seedlings, 2006, C.A. Rodas (CMW 25513; FCC 5425; PREM63211-dried culture) (Herron et al. 2015).

\section{Nucleotide sequence accession number}

This Whole Genome Shotgun project has been deposited at DDBJ/ENA/GenBank under the accession 
JACWFA000000000. The version described in this paper is version JACWFA010000000.

\section{Materials and methods}

The Fusarium sororula isolate was grown on half strength potato dextrose agar (BD Dif $\mathrm{Co}^{\mathrm{TM}}$ ) and genomic DNA was extracted according to the protocol of Möller et al. 1992. One pair-end library (550 bp insert size, read length of $250 \mathrm{bp}$ ) was generated using the Illumina HiSeq 2500 platform at Macrogen (Seoul, Korea). Poor quality and duplicate reads were removed using Qiagen Genomics Workbench v 20.0.4 (CLCBio, Aarhus). Reads were assembled using SPAdes v 3.13.0 (Bankevich et al. 2012). Completeness of the genome assembly was evaluated with BUSCO v 4.0.6 (Seppey et al. 2019), using the hypocreales dataset. Annotation was done with the MAKER annotation pipeline (Cantarel et al. 2008) using Augustus (Stanke et al. 2006a, 2006b), Genemark ES (Ter-Hovhannisyan et al. 2008) and SNAP (Korf 2004). Gene model data from $F$. circinatum (Wingfield et al. 2012), F. fujikuroi (Wiemann et al. 2013), F. verticillioides and F. graminearum (Ma et al. 2010), as well as $F$. mangiferae and $F$. proliferatum (Niehaus et al. 2017), were included as additional evidence.

\section{Results and discussion}

The genome sequence of $F$. sororula was assembled into 328 scaffolds with a total genome size of $47,806,863 \mathrm{bp}$. The N50 value was $1,089,458 \mathrm{bp}$ and the genome had a $\mathrm{G}+\mathrm{C}$ content of $45.99 \%$. BUSCO analyses showed that the assembly was $99.9 \%$ complete [4486 complete and single-copy BUSCOs, 7 complete and duplicated BUSCOs; 2 fragmented BUSCOs, 6 missing BUSCOs; $n=$ 4494]. A total of 15,668 open reading frames (orfs) were predicted using the MAKER annotation pipeline, with a gene density of 327.74 orfs/Mb. Sequence comparisons indicated that all twelve known chromosomes typical for species in the FFSC are present. Phylogenetic analysis of sequences from the sequenced genome confirmed the taxonomic identity of the sequenced Fusarium strain as F. sororula (Fig. 2).

This genome announcement is the third for a Fusarium species isolated from Pinus species in Colombia. The two previously sequenced and assembled genomes where for F. fracticaudum (Wingfield et al. 2018a) and $F$. pininemorale (Wingfield et al. 2017). This genome assembly for $F$. sorula is comparable to other American clade species from the FFSC isolated from Pinus species (Table 2; Wingfield et al. 2018a; Wingfield et al. 2017; Wingfield et al. 2018b), with genome size, $\mathrm{G}+\mathrm{C}$ content and gene density all in a similar range.
Authors: Lieschen De Vos", Magriet A. van der Nest, Quentin C. Santana, Emma T. Steenkamp, Brenda D. Wingfield

"Contact: lieschen.bahlmann@fabi.up.ac.za

\section{IMA GENOME - F 14C}

Draft nuclear genome assembly of Chalaropsis populi, the second genome from the genus Chalaropsis Introduction

Chalaropsis populi is a soil-borne root-pathogen in the family Ceratocystidaceae (Paulin-Mahady et al. 2002; de Beer et al. 2014). The first record of Ch. populi is from the early 1970's where it was isolated from the bark of Populus and Salix spp. in Belgium (Veldeman 1971). This species was referred to as Chalaropsis populi, but no validly published description ever appeared (Kiffer and Delon 1983). Kiffer and Delon (1983) subsequently validated the name Chalaropsis populi, as Chalara populi, but in 2002 this species was once again redescribed and included in Thielaviopsis as T. populi (Paulin-Mahady et al. 2002). Most recently, the genus Chalaropsis was re-established and now includes three named species: Ch. ovoidea, Ch. populi, and Ch. thielavioides, although some evidence supports the recognition of a fourth taxon (de Beer et al. 2014).

Species of Chalaropsis are not considered of significant ecological or economic importance despite being predominantly isolated from diseased plant material (de Beer et al. 2014). The type species of the genus, Ch. thielavioides, is commonly associated with postharvest moulding of carrot (Weber and Tribe 2004; Milosavljević et al. 2015; Xu et al. 2020), although the economic impact of the disease is negligible. Chalaropsis ovoidea is predominantly isolated from Fagus trees (and discoloured planks produced from the wood), but can occasionally be found in Quercus species as well (Nag Raj and Kendrick 1976; Kraj and Kowalski 2005). Chalaropsis populi was originally isolated from brown spots associated with trunk scab disease in Populus and Salix, prompting its description as a cambium killer (Kiffer and Delon 1983). A subsequent study also found Ch. populi in combination with other fungi from diseased roots of Populus and Euramericana trees, but the authors considered it a weak pathogen (Szabó and Harrington 2004).

The low level of importance of these pathogens has resulted in very little research effort focussed on Chalaropsis species. Nevertheless, the taxonomic positioning of Chalaropsis as a sister genus to many important pathogens in the genera Berkeleyomyces, Ceratocystis, and Endoconidiophora make this group of interest. A draft genome for Ch. thielavioides was generated by the RIKEN Center for Life Science 




Fig. 2 Maximum Likelihood tree based on the partial gene sequences of translation elongation factor 1-a and $\beta$-tubulin (Herron et al. 2015). Sequence alignments were assembled with MAFFT $\vee 7.472$ (Katoh et al. 2019). The program jModelTest v 2.1.10 (Darribo et al. 2012) was used to determine the best-fit substitution model (GTR + I $+G$ substitution model) with gamma correction (Tavare 1986). A maximum Likelihood (ML) phylogenetic analysis was performed using PhyML $\vee 3.1$ (Guindon et al. 2010). Values at branch nodes are the bootstrapping confidence values with those $\geq 85 \%$ shown. The F. sororula isolate sequenced in this study is indicated in bold

Technologies, Division of Genomic Technologies, and is publicly available (GCA_001599435.1) (JCM-Riken 2016). In the current study, a draft genome sequence for Ch. populi is presented to accompany that of $C h$. thielavioides. It is hoped that the availability of two genome sequences for Chalaropsis species will support future studies on comparative genomics, while also addressing the taxonomic complexities associated with asexual fungi.

\section{Sequenced strain}

Belgium: Gent: Moerzeke Populetum, isol. from necrosis in Populus gelrica, 1970, R. Veldeman (CMW 26388, CBS 486.71, CBS H-10141 - dried culture).

\section{Nucleotide sequence accession number}

This Whole Genome Shotgun project for Chalaropsis populi isolate CMW 26388 has been deposited at DDBJ/ ENA/GenBank under the accession JADILG000000000.

Table 2 Genome statistics for Fusarium sororula and its close relatives

\begin{tabular}{|c|c|c|c|c|c|}
\hline & Genome size (Mb) & GC content (\%) & Predicted orfs ${ }^{a}$ & Gene density (orfs/Mb) & References \\
\hline F. sororula & 47.81 & 45.99 & 15,688 & 327.74 & This study \\
\hline F. fracticaudum & 45.80 & 47.56 & 14,136 & 308.67 & Wingfield et al. (2018a) \\
\hline F. pininemorale & 47.78 & 45.98 & 15,455 & 323.47 & Wingfield et al. (2017) \\
\hline F. circinatum & 45.10 & 46.97 & 15,091 & 334.61 & Wingfield et al. (2018b) \\
\hline
\end{tabular}

${ }^{\mathrm{a}}$ Determined as described in text 


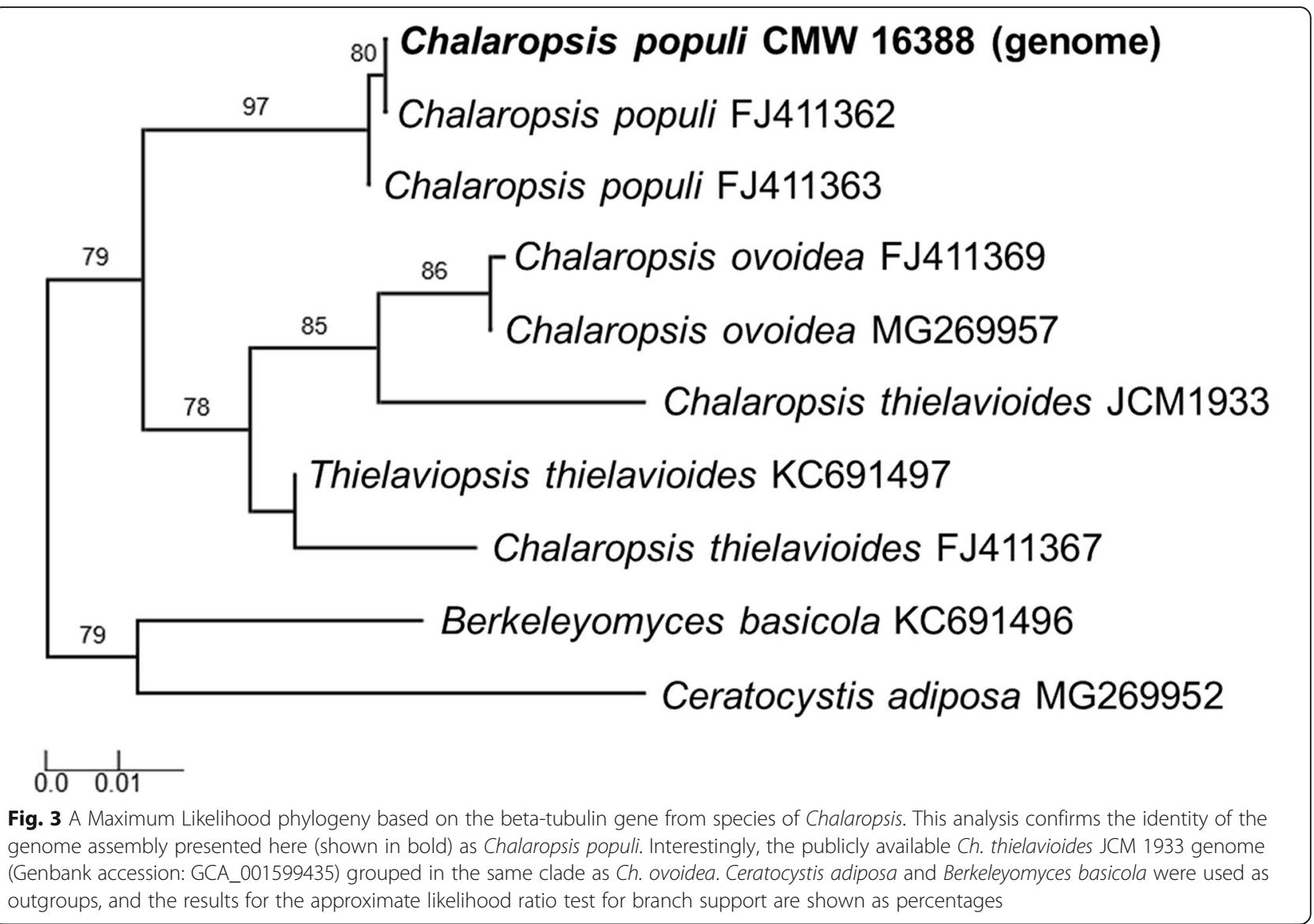

The version described in this paper is version JADILG010000000.

\section{Materials and methods}

Chalaropsis populi isolate CMW 26388 was obtained from the culture collection (CMW) of the Forestry and Agricultural Biotechnology Institute (FABI) based at the University of Pretoria and grown on $2 \%$ malt extract agar (MEA: 2\% w/v, Biolab, South Africa) at $25^{\circ} \mathrm{C}$ for the duration of the study. Genomic DNA was isolated from a 14-day old culture grown on a cellophane sheet using the DNeasy Plant Mini Kit (Qiagen, Germany). The isolated DNA was sent to the Agricultural Research Council Biotechnology Platform (ARC-BTP; Pretoria, South Africa) where it was used to prepare a pair-end library with an insert size of $500 \mathrm{bp}$. An Illumina HiSeq 2500 (Illumina, San Diego, CA) was used to generate $125 \mathrm{bp}$ length reads from both ends of the insert.

The raw reads generated were imported and trimmed (using the Trim Sequences command and default values) in CLC Genomics Workbench v. 20.0.3 (CLCBio, Aarhus) before being used in a de novo assembly to generate a draft genome sequence. The untrimmed paired reads were also used for read-error correction and assembly with SPAdes v.
3.14.0 (Bankevich et al. 2012) using custom K-values (21, 33, $55,77)$, applying the "careful" option to reduce mismatches and including the CLC-generated scaffolds as untrusted contigs. An estimation of the number of protein coding genes in the Ch. populi genome was made using the AUGUSTUS de novo prediction software with Fusarium graminearum gene models (Stanke et al. 2006a, 2006b; Keller et al. 2011). General genome statistics (genome length, GC content, N50 and L50 values) for the Ch. populi assembly were calculated using QUAST v. 5.0.1 (Gurevich et al. 2013), while both this genome and the Ch. thielavioides JCM 1933 assembly (JCMRiken 2016) was assessed for completeness using the Benchmarking Universal Single Copy Orthologs tool (BUSCO v. 4.0.6) (Simão et al. 2015) using both the Fungi_odb10 and Ascomycota_odb10 datasets.

The publicly available genome sequence for $\mathrm{Ch}$. thielavioides JCM 1933 was retrieved from the genome repository at the National Center for Biotechnology Information (NCBI) (JCM-Riken 2016). The beta-tubulin gene was extracted from the draft genome assemblies of both Ch. populi CMW 26388 and Ch. thielavioides JCM 1933 using CLC Genomics Workbench. These were used together with published sequences from $\mathrm{Ch}$. ovoidea, Ch. thielavioides, Ch. populi, Ceratocystis adiposa 
and Berkeleyomyces basicola in a phylogenetic analysis to confirm the identity of the sequenced strains (Fig. 3). To do this, the one click mode phylogeny online tool (Dereeper et al. 2008, 2010) that included MUSCLE alignment (Edgar 2004), curation via Gblocks (Castresana 2000), PhyML steps (Guindon and Gascuel 2003) and a Maximum Likelihood test for branch support was used (Anisimova and Gascuel 2006). The tree was rooted using Ceratocystis adiposa and Berkeleyomyces basicola.

\section{Results and discussion}

The draft genome sequence of Ch. populi had a length of 23,877,278 bp present in 2158 contigs, of which 1398 were larger than $1000 \mathrm{bp}$. The genome had a GC content of $52.56 \%$, an average coverage of $81 x$, a N50 value of 29,267 bp and a L50 value of 239. AUGUSTUS predicted 6654 protein coding genes, while BUSCO analysis reported a completeness score of 96.7 and $98.0 \%$ for $C h$. populi for the respective Ascomycota and Fungi BUSCO datasets. This was based on the analysis of 1706 and 758 orthologs for the Ascomycota and Fungi datasets respectively, where 1650 and 743 were present and complete, while 48 and 13 copies were completely absent. The comparative BUSCO analysis for the Ch. thielavioides JCM 1933 genome assembly indicated a 84.1\% (1435 complete and 266 missing BUSCOs) and 85.8\% (650 complete and 108 missing BUSCOs) completeness for the Ascomycota and Fungi dataset.

Phylogenetic analysis using the beta-tubulin gene from the sequenced genome confirmed the identity of the isolate as Ch. populi (Fig. 3), although the publicly available genome sequence for Chalaropsis thielavioides JCM 1933 grouped closer to Ch. ovoidea than known Ch. thielavioides strains. When compared to the Ch. thielavioides genome, Ch. populi has a similar genome size $(23,8 \mathrm{Mb}$ for Ch. populi vs 23,3 $\mathrm{Mb}$ for Ch. thielavioides), although it is more fragmented (2158 vs 252 contigs) (JCM-Riken 2016). This is supported by the N50 values $(29,267 \mathrm{bp}$ for $\mathrm{Ch}$. populi vs $161,617 \mathrm{bp}$ for Ch. thielavioides). However, the Ch. populi genome was more complete based on the BUSCO assessments.

The Ch. populi draft assembly is the second genome sequence available for a Chalaropsis sp. This will support research efforts aimed at understanding the biology of these understudied fungal pathogens (Weber and Tribe 2004). For example, all three known species of Chalaropsis are considered asexual (de Beer et al. 2014), a stark contrast to the predominantly sexual species in the Ceratocystidaceae. Much work has been focussed on sexual reproduction in the family (e.g. Wilken et al. 2017; Nel et al. 2018; Simpson et al. 2018), and the availability of two genome sequences for putatively asexual members will be a valuable addition to this ongoing project. Together with the Ch. populi sequence, there are now 30 species residing in Ceratocystidaceae of which the genomes have been sequenced and these include representatives of ten genera (https://www.ncbi.nlm.nih.gov/datasets/genomes/?txid= $1028423 \&$ ter $m=$ Ceratocystidaceae\&utm_source $=$ assembly\&utm_medium $=$ referral\&utm_campaign=: assemb). These sequences provide the opportunity to perform family-level analyses seeking to answer questions regarding speciation processes, host adaptations, and comparative genomics. They will also provide a basis for further functional studies (e.g. Sayari et al. 2019; Wilson et al. 2020) in Ceratocystidaceae.

Authors: Jostina R. Rakoma, Frances A. Lane, P. Markus Wilken*

* Contact: Markus.Wilken@fabi.up.ac.za

\section{IMA GENOME- F 14D}

\section{Draft genome sequence of Chrysoporthe puriensis: the cause of a canket disease on Eucalyptus and Tibouchina Introduction}

The genus Chrysoporthe accommodates numerous economically important pathogens of plantation Eucalyptus species and other members of Myrtales (Gryzenhout et al. 2009). These fungi cause serious stem canker diseases, predominantly in tropical and subtropical parts of the world (Wingfield 2003). Chrysoporthe puriensis was first reported causing a stem canker disease on Tibouchina spp. in Brazil (Oliveira et al. 2021). Pathogenicity tests showed that $C$. puriensis is pathogenic on the hybrid Eucalyptus grandis $\times$ E. urophylla, suggesting that the fungus could threaten commercially-grown Eucalyptus plantations in South America (Oliveira et al. 2021). Similar to other Chrysoporthe spp. causing stem cankers on trees, C. puriensis is a potential threat to trees in Myrtales grown as non-natives for commercial purposes or where they are native. Countries such as Australia that has a mega-diverse Myrtales flora are especially vulnerable to these relatively wide host range pathogens (Burgess and Wingfield 2017); as has been seen for the globally spreading myrtle rust pathogen Austropuccinia psidii (Glen et al. 2007; Roux et al. 2016).

Genome sequences are available for three species of Chrysoporthe, which infect Eucalyptus. These include, $C$. austroafricana, C. cubensis, and C. deuterocubensis (Wingfield et al. 2015a, 2015b). The aim of this study was to sequence and assemble the genome of $C$. puriensis that will enable comparative genome studies focussed on further understanding the biology of Chrysoporthe species and to improve disease management strategies for them.

\section{Sequenced strain}

Brazil: Minas Gerais: Silveirânia, Tibouchina granulosa, 2018, M.E.S. Oliveira (CMW 54409). 


\section{Sequence accession numbers}

The genome sequence of Chrysoporthe puriensis (isolate number CMW 54409) has been deposited in DDBJ/ EMBL/GenBank databases under the accession numbers CP064894 - CP064907.

\section{Materials and methods}

Genomic DNA was extracted from freeze-dried mycelium of isolate CMW 54409 grown in malt yeast broth (2\% malt extract, $0.5 \%$ yeast extract; Biolab, Midrand, South Africa) using the Qiagen ${ }^{\circledR}$ Genomictip DNA extraction protocol for plants and fungi. To verify the identification of the isolate, sequencing of the internal transcribed spacer (ITS) region and the partial $\beta$-tubulin gene ( $t u b 1$ and $t u b 2$ ) was performed. The reference sequences were obtained from GenBank. Amphilogia gyrosa was used as an outgroup. Sequence datasets were aligned using an online version of MAFFT v.7 (Katoh and Standley 2013). A maximum likelihood analysis was performed using RAxML (Stamatakis 2014) using the GTR + G substitution model and branch support was calculated using 1000 bootstrap replicates.

Nanopore sequencing was conducted using the MinION sequencing device. The sequencing library was prepared using the Genomic DNA by Ligation (SQKLSK109) protocol. The library was loaded on a MinION flow cell (R10.3) and sequencing run was carried out for

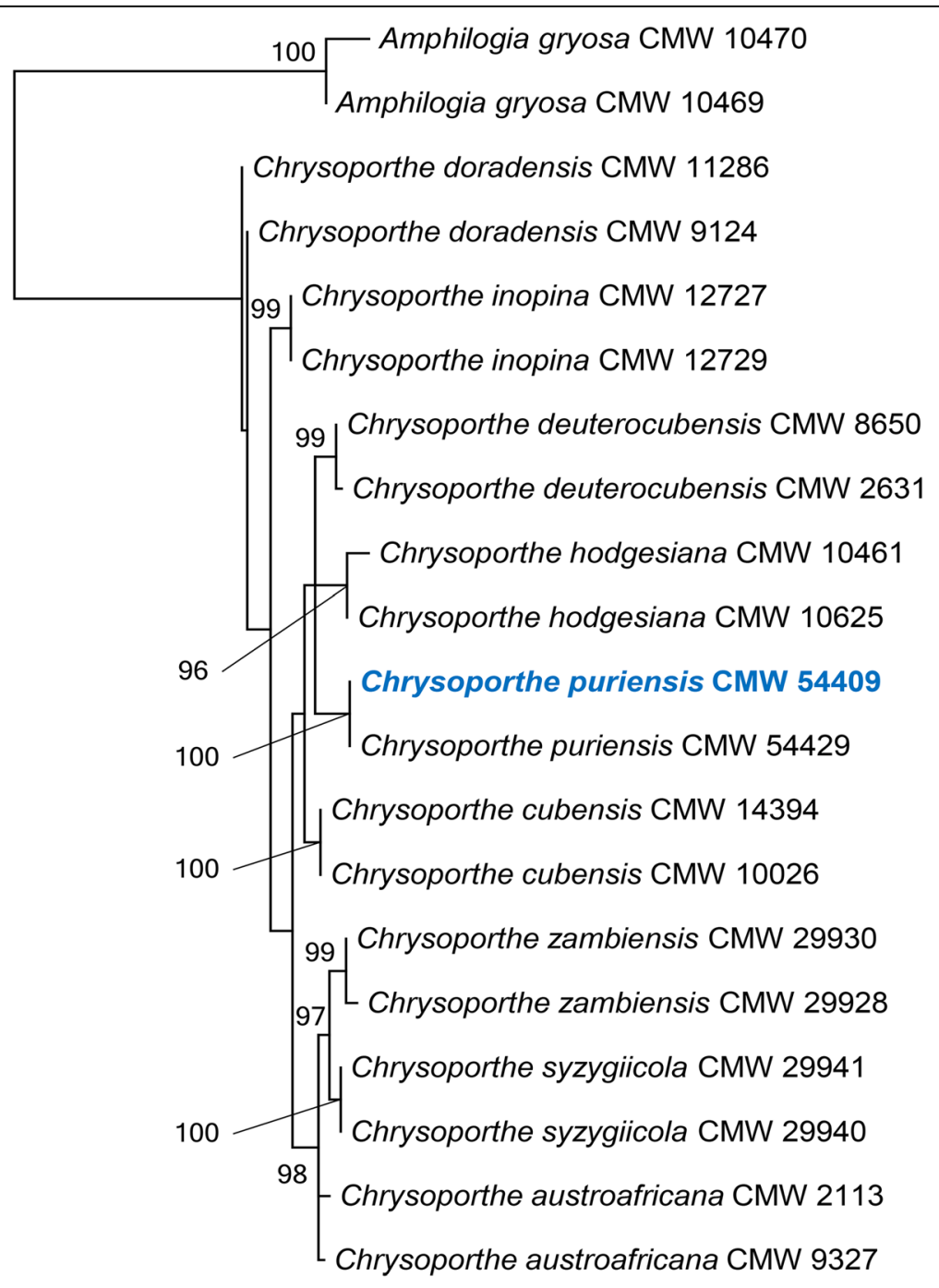

$\mathrm{H}$ 0.0020

Fig. 4 Maximum Likelihood tree based on ITS region and partial gene sequences of but 1 and but2. Bootstrap values $\geq 65 \%$ are shown. The isolates used in this study are indicated in blue and bold 
$48 \mathrm{~h}$. Base calling was conducted using ONT Guppy basecalling software $\mathrm{v}$ 4.0.14.

Nanopore reads were trimmed using Porechop (v0.2.1, https:/github.com/rrwick/Porechop). The genome was assembled using Flye v 2.7 (Kolmogorov et al. 2019). The assembly was polished using Rebaler v0.2.0 (Wick et al. 2019), which runs multiple rounds of Racon v1.4.13 (Vaser et al. 2017) and followed by two rounds of polishing iterations with Medaka v1.0.3 (https:// github.com/nanoporetech/medaka). Protein coding gene models were annotated using AUGUSTUS v.3.3 with Magnaporthe grisea as the model organism (Stanke and Morgenstern 2005). The assembled genome completeness was evaluated using the Benchmarking Universal Single-Copy Orthologs tool, BUSCO v. 4.1.3 by using the fungal lineage dataset (Simão et al. 2015).

\section{Results and discussion}

Phylogenetic analysis using three gene regions (ITS, $t u b 1$, and $t u b 2$ ) confirmed the taxonomic identity of isolate CMW 54409 as C. puriensis (Fig. 4). The assembly of C. puriensis consisted of 14 contigs, with the N50 of $4.78 \mathrm{Mb}$ and L50 of 5. The calculated genome size was approximately $44.66 \mathrm{Mb}$ and with a CG content of $53.91 \%$. AUGUSTUS predicted 13,166 protein coding gene models in the assembled genome. BUSCO analysis using the sordariomycetes_odb10 dataset indicated the assembled genome to have a $98.3 \%$ completeness score. Of the 3817 BUSCO groups searches, 13 BUSCO orthologs were reported to be fragmented and 54 BUSCO groups were reported to be missing.

The estimated genome size and gene number for $C$. puriensis is similar to that of other Chrysoporthe species: Chrysoporthe ausroafricana (44.6 Mb, 13,484) (Wingfield et al. 2015a), C. cubensis $(42.6 \mathrm{Mb}, 13,121)$ (Wingfield et al. 2015b), C. deuterocubensis (43.9 Mb; 13,772) (Wingfield et al. 2015b). The draft genome sequence of C. puriensis generated here will be used for comparative genomics studies as well as to better understand its, biology and role as a tree pathogen.. Furthermore, the genome sequence will be useful for to develop molecular markers for population studies of the species and to determine its origin and pathways of movement in forests.

Authors: H. Suzuki, T.A. Duong*, M.A. Ferreira, M.J. Wingfield, B.D. Wingfield "Contact: Tuan.Duong@fabi.up.ac.za

\section{Acknowledgements}

The authors of the contribution of Penicillium roqueforti CECT $2905^{\top}$ thank the support of DICYT-USACH. The authors of Penicillium roqueforti CECT $2905^{\top}$ study acknowledge the financial support of FONDECYT-Chile (projects numbers 1120833, 1150894 and 1170799) and CONICYT-Chile (fellowship CONICYT-PFCHA/Doctorado Nacional/2014-63140056). The authors thank the University of Pretoria, the Department of Science and Technology (DST)/National Research Foundation (NRF) Centre of Excellence in Tree Health Biotechnology (CTHB), South Africa, the Tree Protection Co-operative
Programme (TPCP), the National Research Foundation and the DST-NRF SARChl chair in Fungal Genomics.

Adherence to national and international regulations Not applicable.

\section{Authors' contributions}

The authors read and approved the final manuscript.

Ethics approval and consent to participate

Not applicable.

\section{Consent for publication}

Not applicable.

\section{Competing interests}

The authors declare that they have no competing interests.

\section{Author details}

'Department of Biochemistry, Genetics and Microbiology, Forestry and Agricultural Biotechnology Institute (FABI), University of Pretoria, Private bag X20, Pretoria 0028, South Africa. ${ }^{2}$ Biotechnology Platform, Agricultural Research Council, Onderstepoort, Pretoria 0110, South Africa. ${ }^{3}$ Departamento de Biología, Facultad de Química y Biología, Universidad de Santiago de Chile (USACH), Alameda 3363, Estación Central, 9170022 Santiago, Chile. ${ }^{4}$ Department of Plant Pathology, Universidade Federal de Lavras/UFLA, Lavras, MG 37200-000, Brazil. ${ }^{5}$ Departamento de Química, Facultad de Ciencias, Universidad de Chile, Las Palmeras 3425, Ñuñoa, Santiago, Chile.

Published online: 05 March 2021

\section{References}

Anisimova M, Gascuel O (2006) Approximate likelihood ratio test for branches: a fast, accurate and powerful alternative. Syst Biol 55:539-552

Bainbridge BW, Spreadbury CL, Scalise FG, Cohen J (1990) Improved methods for the preparation of high molecular weight DNA from large and small scale cultures of filamentous fungi. FEMS Microbiol Letters 54:113-117

Bankevich A, Nurk S, Antipov D, Gurevich AA, Dvorkin M et al (2012) SPAdes: a new genome assembly algorithm and its applications to single-cell sequencing. J Comput Biol 19:455-477

Blin K, Shaw S, Steinke K, Villebro R, Ziemert N et al (2019) antiSMASH 5.0: updates to the secondary metabolite genome mining pipeline. Nucleic Acids Research 47:W81-W87

Bolger AM, Lohse M, Usadel B (2014) Trimmomatic: a flexible trimmer for Illumina sequence data. Bioinformatics 30:2114-2120

Burgess TI, Wingfield MJ (2017) Pathogens on the move: a 100-year global experiment with planted eucalypts. Bioscience 67:14-25

Cantarel BL, Korf I, Robb SMC, Parra G, Ross E et al (2008) MAKER: an easy-to-use annotation pipeline designed for emerging model organism genomes. Genome Res 18:188-196

Castresana J (2000) Selection of conserved blocks from multiple alignments for their use in phylogenetic analysis. Mol Biol Evol 17:540-552

Chávez R, Fierro F, García-Rico RO, Laich F (2011) Mold-fermented foods: Penicillium spp. as ripening agents in the elaboration of cheese and meat products. In: Leitao AL (ed) Mycofactories. Bentham Science Publisher Ltd, United Arab Emirates.

Cheeseman K, Ropars J, Renault P, Dupont J, Gouzy J et al (2014) Multiple recent horizontal transfers of a large genomic region in cheese making fungi. Nature Communications 5:2876

Coton E, Coton M, Hymery N, Mounier J, Jany J-L (2020) Penicillium roqueforti: an overview of its genetics, physiology, metabolism and biotechnological applications. Fungal Biol Rev 34:59-73

Darribo D, Taboada GL, Doallo R, Posada D (2012) jModelTest 2: more models, new heuristics and parallel computing. Nat Methods 9:772

de Beer ZW, Duong TA, Barnes I, Wingfield BD, Wingfield MJ (2014) Redefining Ceratocystis and allied genera. Stud Mycol 79:87-219

Del-Cid A, Gil-Durán C, Vaca I, Rojas-Aedo JF, García-Rico RO et al (2016) Identification and functional analysis of the mycophenolic acid gene cluster of Penicillium roqueforti. PLoS One 11:e0147047

Dereeper A, Audic S, Claverie JM, Blanc G (2010) BLAST-EXPLORER helps you building datasets for phylogenetic analysis. BMC Evol Biol 10:8 
Dereeper A, Guignon V, Blanc G, Audic S, Buffet S et al (2008) Phylogeny.fr: robust phylogenetic analysis for the non-specialist. Nucleic Acids Res 36 : W465-W469

Edgar RC (2004) MUSCLE: multiple sequence alignment with high accuracy and high throughput. Nucleic Acids Res 32:1792-1797

Fernández-Bodega Á, Álvarez-Álvarez R, Liras P, Martín JF (2017) Silencing of a second dimethylallyltryptophan synthase of Penicillium roqueforti reveals a novel clavine alkaloid gene cluster. Appl Microbiol Biotechnol 101:6111-6121

Frisvad JC, Samson RA (2004) Polyphasic taxonomy of Penicillium subgenus Penicillium - a guide to identification of food and air-borne terverticillate Penicillia and their mycotoxins. Stud Mycol 49:1-173

García-Rico RO, Chávez R, Fierro F, Martín JF (2009) Effect of a heterotrimeric G protein a subunit on conidia germination, stress response, and roquefortine C production in Penicillium roqueforti. Int Microbiol 12:123-129

Gil-Durán C, Rojas-Aedo JF, Medina E, Vaca I, García-Rico RO, Villagrán S et al (2015) The pczl gene, which encodes a $\mathrm{Zn}(\mathrm{II})_{2} \mathrm{Cys}_{6}$ protein, is involved in the control of growth, conidiation, and conidial germination in the filamentous fungus Penicillium roqueforti. PLoS One 10:e0120740

Glen M, Aflenas AC, Zauza EAV, Wingfield MJ, Mohammed C (2007) Puccinia psidii: a threat to the Australian environment and economy - a review. Australasian Plant Pathology 36:1-16

Gryzenhout M, Wingfield BD, Wingfield MJ (2009) Taxonomy, phylogeny, and ecology of bark-inhabiting and tree-pathogenic fungi in the Cryphonectriaceae. The American Phytopathological Society, St. Paul, Minnesota U.S.A

Guevara-Suarez M, García D, Cano-Lira JF, Guarro J, Gené J (2020) Species diversity in Penicillium and Talaromyces from herbivore dung, and the proposal of two new genera of penicillium-like fungi in Aspergillaceae. Fungal Syst Evol 5:39-75

Guindon S, Dufayard J-F, Lefort V, Anisimova M, Hordijk W et al (2010) New algorithms and methods to estimate maximum- likelihood phylogenies: Assessing the performance of PhyML 3.0. Systematic Biology 59:307-21

Guindon S, Gascuel O (2003) A simple, fast, and accurate algorithm to estimate large phylogenies by maximum likelihood. Syst Biol 52:696-704

Gurevich A, Saveliev V, Vyahhi N, Tesler G (2013) QUAST: quality assessment tool for genome assemblies. Bioinformatics 29:1072-1075

Herron DA, Wingfield MJ, Rodas CA, Marincowitz S, Steenkamp ET (2015) Novel taxa in the Fusarium fujikuroi species complex from Pinus spp. Stud Mycol 80:131-150

Hidalgo PI, Ullán RV, Albillos SM, Montero O, Fernández-Bodega MÁ et al (2014) Molecular characterization of the PR-toxin gene cluster in Penicillium roqueforti and Penicillium chrysogenum: cross talk of secondary metabolite pathways. Fungal Genet Biol 62:11-24

Houbraken J, Kocsubé S, Visagie CM, Yilmaz N, Wang X-C et al (2020) Classification of Aspergillus, Penicillium, Talaromyces and related genera (Eurotiales): an overview of families, genera, subgenera, sections, series and species. Stud Mycol 95:5-169

JCM-Riken BioResource Center (2016) NBRP: Genome sequencing of Chalaropsis thielavioides JCM 1933

Katoh K, Rozewick J, Yamada KD (2019) MAFFT online service: multiple sequence alignment, interactive sequence choice and visualization. Brief Bioinform 20: 1160-1166

Katoh K, Standley DM (2013) MAFFT multiple sequence alignment software version 7: improvements in performance and usablility. Mol Biol Evol 30:772-780

Keller O, Kollmar M, Stanke M, Waack S (2011) A novel hybrid gene prediction method employing protein multiple sequence alignments. Bioinformatics 27 : 757-763

Kiffer E, Delon R (1983) Chalara elegans (Thielaviopsis basicola) and allied species. II - validation of two taxa. Mycotaxon 18:165-174

Kolmogorov M, Yuan J, Lin Y, Pevzner PA (2019) Assembly of long, error-prone reads using repeat graphs. Nat Biotechnol 37:540-546

Korf I (2004) Gene finding in novel genomes. BMC Bioinformatics 5:59

Kosalková K, Domínguez-Santos R, Coton M, Coton E, García-Estrada C et al (2015) A natural short pathway synthesizes roquefortine $C$ but not meleagrin in three different Penicillium roqueforti strains. Appl Microbiol Biotechnol 99:7601-7612

Kraj W, Kowalski T (2005) Identification of the polish strains of Chalara ovoidea using RAPD molecular markers. Acta Societatis Botanicorum Poloniae 74:35-42

Kumar S, Stecher G, Li M, Knyaz C, Tamura K (2018) MEGA X: molecular evolutionary genetics analysis across computing platforms. Mol Biol Evol 35 1547-1549

Kvas M, Marasas WFO, Wingfield BD, Wingfield MJ, Steenkamp ET (2009) Diversity and evolution of Fusarium species in the Gibberella fujikuroi complex. Fungal Diversity $34: 1-21$
Langmead B, Salzberg SL (2012) Fast gapped-read alignment with bowtie 2. Nat Methods 9:357-359

Leslie JF, Summerell BA (2006) The Fusarium laboratory manual. Blackwell, lowa

Ma L-J, Van der Does HC, Borkovich KA, Coleman JJ, Daboussi M-J et al (2010) Comparative genomics reveals mobile pathogenicity chromosomes in Fusarium. Nature 464:367-373

Milosavljević A, Trkulja N, Popović T, Ivanović Ž, Mitrović M et al (2015) First report of Thielaviopsis thielavioides, a causal agent of postharvest blackening on Daucus carota in Serbia. Plant Disease 99:1274-1275

Möller EM, Bahnweg G, Sandermann H, Geiger HH (1992) A simple and efficient protocol for isolation of high molecular weight DNA from filamentous fungi, fruit bodies, and infected plant tissues. Nucleic Acids Res 20:6115-6116

Nag Raj TR, Kendrick B (1976) A monograph of Charala and allied genera. Wilfrid Laurier University Press, Waterloo

Nel WJ, Duong TA, Wingfield MJ, Wingfield BD, Hammerbacher A et al (2018) Heterothallism revealed in the root rot fungi Berkeleyomyces basicola and $B$. rouxiae. Fungal Biol 122:1031-1040

Niehaus EM, Münsterkötter M, Proctor RH, Brown DW, Sharon A et al (2017) Comparative "omics" of the Fusarium fujikuroi species complex highlights differences in genetic potential and metabolite synthesis. Genome Biol Evol 8:3574-3599

Oliveira MES, van der Merwe NA, Wingfield MJ, Wingfield BD, Soares TPF et al (2021) Chrysoporthe puriensis sp. nov. from Tibouchine spp. in Brazil: an emerging threat to Eucalyptus. Australasian Plant Pathol 50:29-40

Paulin-Mahady AE, Harrington TC, McNew D (2002) Phylogenetic and taxonomic evaluation of Chalara, Chalaropsis, and Thielaviopsis anamorphs associated with Ceratocystis. Mycologia 94:62-72

Rojas-Aedo JF, Gil-Durán C, Del-Cid A, Valdés N, Álamos P et al (2017) The biosynthetic gene cluster for andrastin a in Penicillium roqueforti. Front Microbiol 8:813

Rojas-Aedo JF, Gil-Durán C, Goity A, Vaca I, Levicán G et al (2018) The developmental regulator Pcz1 affects the production of secondary metabolites in the filamentous fungus Penicillium roqueforti. Microbiol Res 212:67-74

Roux J, Granados GM, Shuey L, Barnes I, Wingfield MJ, McTaggart AR (2016) A unique genotype of the rust pathogen, Puccinia psidii, on Myrtaceae in South Africa. Australasian Plant Pathol 45:645-652

Sayari M, van der Nest MA, Steenkamp ET, Adegeye OO, Marincowitz S et al (2019) Agrobacterium-mediated transformation of Ceratocystis albifundus. Microbiol Res 226:55-64

Seppey M, Manni M, Zdobnov EM (2019) BUSCO: assessing genome assembly and annotation completeness. In: Kollmar M (ed) Gene prediction: methods and protocols, methods in molecular biology. Humana, New York

Simão FA, Waterhouse RM, loannidis P, Kriventseva EV, Zdobnov EM (2015) BUSCO: assessing genome assembly and annotation completeness with single-copy orthologs. Bioinformatics 31:3210-3212

Simpson MC, Coetzee MPA, van der Nest MA, Wingfield MJ, Wingfield BD (2018) Ceratocystidaceae exhibit high levels of recombination at the mating-type (MAT) locus. Fungal Biol 122:1184-1191

Stamatakis A (2014) RAxML version 8: a tool for phylogenetic analysis and postanalysis of large phylogenies. Bioinformatics 30:1312-1313

Stanke M, Diekhans M, Baertsch R, Haussler D (2008) Using native and syntenically mapped cDNA alignments to improve de novo gene finding. Bioinformatics 24:637-644

Stanke M, Morgenstern B (2005) AUGUSTUS: a web server for gene prediction in eukaryotes that allows user-defined constraints. Nucleic Acids Res 33:W465-W467

Stanke M, Schöffmann O, Morgenstern B, Waack S (2006a) Gene prediction in eukaryotes with a generalized hidden Markov model that uses hints from external sources. BMC Bioinformatics 7:62

Stanke M, Tzvetkova A, Morgenstern B (2006b) AUGUSTUS at EGASP: using EST, protein and genomic alignments for improved gene prediction in the human genome. Genome Biol 7:S11

Steenkamp ET, Rodas CA, Kvas M, Wingfield BD (2012) Fusarium circinatum and pitch canker of Pinus in Colombia. Australasian Plant Pathol 41:483-491

Szabó I, Harrington TC (2004) First report of Thielaviopsis populi on hybrid poplar in Hungary. Plant Pathol 53:249-249

Tavare S (1986) Some probabilistic and statistical problems in the analysis of DNA sequences. In: Muira RM (ed) Some mathematical questions in biology: DNA sequence analysis. The American Mathematical Society, Providence, Rhode Island

Ter-Hovhannisyan V, Lomsadze A, Chernoff YO, Borodovsky M (2008) Gene prediction in novel fungal genomes using an ab initio algorithm with unsupervised training. Genome Research 18:1979-1990 
Thom C (1906) Fungi in cheese ripening: camembert and Roquefort. U.S.D.A. Bureau Anim Industry Bull 82:1-39

Torrent C, Gil-Durán C, Rojas-Aedo JF, Medina E, Vaca I et al (2017) Role of sfk1 gene in the filamentous fungus Penicillium roqueforti. Front Microbiol 8:2424

Vaser R, Sovic I, Nagarajan N, Sikic M (2017) Fast and accurate de novo genome assembly from long uncorrected reads. Genome Res 27:737-746

Veldeman R (1971) 'Chalaropsis sp.' a new parasitic fungus on poplar, the cause of bark lesions. Mededelingen van de Facultiet Landbouwwetenschappen, Rijksuniversiteit Gent 36:1001-1005

Weber RW, Tribe HT (2004) Thielaviopsis basicola and T. thielavioides, two ubiquitous moulds on carrots sold in shops. Mycologist 18:6-10

Wick RR, Judd LM, Holt KE (2019) Performance of neural network basecalling tools for Oxford Nanopore sequencing. Genome Biol 20:129-138

Wiemann P, Sieber CMK, Von Bargen KW, Studt L, Niehaus E-M et al (2013) Unleashing the cryptic genome: genome-wide analyses of the rice pathogen Fusarium fujikuroi reveal complex regulation of secondary metabolism and novel metabolites. PLoS Pathogens 9:e1003475

Wilken PM, Steenkamp ET, van der Nest MA, Wingfield MJ, de Beer ZW et al (2017) Unexpected placement of the MAT1-1-2 gene in the MAT1-2 idiomorph of Thielaviopsis. Fungal Genet Biol 113:32-41

Wilson AM, Wilken PM, van der Nest MA, Wingfield MJ, Wingfield BD (2020) The novel Huntiella omanensis mating gene, MAT1-2-7, is essential for ascomatal maturation. Fungal Genet Biol 137:103335

Wingfield BD, Ades PK, Al-Naemi FA, Beirn LA, Bihon W et al (2015a) Draft genome sequences of Chrysoporthe austroafricana, Diplodia scrobiculata, Fusarium nygamai, Leptographium lundbergii, Limonomyces culmigenus, Stagonosporopsis tanaceti, and Thielaviopsos punctulata. IMA Fungus 6:233-248

Wingfield BD, Bames I, De Beer ZW, De Vos L, Duong TA et al (2015b) Draft genome sequences of Ceratocystis eucalypticola, Chrysoporthe cubensis, C. deuterocubensis, Davidsoniella irescens, Fusarium temperatum, Graphilbum fragrans, Penicillium nordicum, and Thielaviopsis musarum. IMA Fungus 6:493-506

Wingfield BD, Berger DK, Steenkamp ET, Lim H-J, Duong TA et al (2017) Draft genome of Cercospora zeina, Fusarium pininemorale, Hawksworthiomyces lignivorus, Huntiella decipiens and Ophiostoma ips. IMA Fungus 8:385-396

Wingfield BD, Bills GF, Dong Y, Huang W, Nel WJ et al (2018a) Draft genome sequence of Annulohypoxylon stygium, Aspergillus mulundensis, Berkeleyomyces basicola (syn. Thielaviopsis basicola), Ceratocystis smalleyi, two Cercospora beticola strains, Coleophoma cylindrospora, Fusarium fracticaudum, Phialophora cf. hyalina, and Morchella septimelata. IMA Fungus 9:199-223

Wingfield BD, Liu M, Nguyen HDT, Lane FA, Morgan SW et al (2018b) Nine draft genome sequences of Claviceps purpurea s. lat., including C. arundinis, C. humidiphila, and C. cf. spartinea, pseudomolecules for the pitch canker pathogen Fusarium circinatum, draft genome of Davidsoniella eucalypti, Grosmannia galeiformis, Quambalaria euclaypti, and Teratospahaeria destructans. IMA Fungus 9:401-418

Wingfield BD, Steenkamp ET, Santana QC, Coetzee MPA, Bam S et al (2012) First fungal genome sequence from Africa: a preliminary analysis. South African Journal of Science 108:1-9

Wingfield MJ (2003) Daniel McAlpine memorial lecture increasing threat of diseases to exotic plantation forests in the southern hemisphere: lessons from Cryphonectria canker. Australasian Plant Pathol 32:133-139

Xu K, Li J, Yang X, Zhang R, Li X et al (2020) Postharvest rot on carrot caused by Ceratocystis fimbriata and Chalaropsis thielavioides (三 Thielaviopsis thielavioides) in China. J Gen Plant Pathol 86:322-325

\section{Publisher's Note}

Springer Nature remains neutral with regard to jurisdictional claims in published maps and institutional affiliations.

Ready to submit your research? Choose BMC and benefit from:
- fast, convenient online submission
- thorough peer review by experienced researchers in your field
- rapid publication on acceptance
- support for research data, including large and complex data types
- gold Open Access which fosters wider collaboration and increased citations
- maximum visibility for your research: over 100M website views per year
At BMC, research is always in progress.
Learn more biomedcentral.com/submissions

